\title{
TEMPORAL PATTERNS OF SOMATOSTATIN IMMUNOREACTIVITY IN THE CEREBROSPINAL FLUID OF THE RHESUS MONKEY: EFFECT OF ENVIRONMENTAL LIGHTING ${ }^{1}$
}

\author{
MICHAEL A. ARNOLD, ${ }^{*, 2}$ STEVEN M. REPPERT, \\ HENRY T. KEUTMANN, | MARK J. PERLOW, „| AND JOSEPH B. MARTIN*,3 \\ *Department of Neurology, $\ddagger$ Children’s Service, and $\rrbracket$ Endocrine Unit, Massachusetts General Hospital and Harvard \\ Medical School, Boston, Massachusetts 02114, \$Faculty of Medicine, Division of Internal Medicine, University of Calgary, \\ Calgary, Alberta T2N 1N4, Canada, and \|Department of Neurology, Mount Sinai Hospital Medical School, \\ New York, New York 10029
}

Received August 21, 1981; Revised December 28, 1981; Accepted January 6, 1982

\begin{abstract}
A rabbit antiserum to somatostatin was used to develop radioimmunoassay methods for measuring somatostatin in monkey cerebrospinal fluid (CSF). By gel permeation chromatography, at least five molecular weight forms of immunoreactive somatostatin (IRS) were identified in monkey CSF; two of these species co-migrated with either synthetic somatostatin-14 or somatostatin-28. The 24-hr profile of CSF somatostatin immunoreactivity was obtained from five monkeys during diurnal lighting, constant light, and constant darkness. During diurnal lighting, all five monkeys had a clear ultradian component in CSF IRS of 4 to $5 \mathrm{hr}$ duration; this pattern was not affected significantly by constant light or dark. In addition, three of the five monkeys exposed to diurnal lighting showed a diurnal rhythm in CSF IRS, with higher hormone levels during darkness. In some animals, this diurnal rhythm also could be demonstrated during constant light or dark.
\end{abstract}

Somatostatin, a tetradecapeptide that inhibits growth hormone (GH) (Brazeau et al., 1973) and thyrotropin release from the pituitary (Vale et al., 1974), has a widespread distribution in the central nervous system as shown by immunohistochemistry and radioimmunoassay (RIA). The highest levels of somatostatin in the rat are found in the medial basal hypothalamus (Brownstein et al., 1975) although substantial levels also have been reported in the preoptic area (Kobayashi et al., 1977) and the circumventricular organs (Palkovits et al., 1979). Subcellular fractionation of brain tissue has indicated that 60 to $80 \%$ of the somatostatin is localized in the synaptosomal fraction (Epelbaum et al., 1977). Pharma-

\footnotetext{
1 These studies were supported in part by United States Public Health Service Grant AM 26252. A portion of these studies was presented at the annual meeting of the American Neurological Association in Boston, MA, September 1980 (Arnold, M. A., S. M. Reppert, O. P. Rorstad, S. M. Sagar, H. T. Keutmann, M. J. Perlow, and J. B. Martin (1980) Ann. Neurol. 8: 104). We would like to thank Drs. Jiuan S. Terman and Michael Terman of the Department of Psychology, Northeastern University for performing power spectral analysis of the cerebrospinal fluid data.

${ }^{2}$ Recipient of a National Institutes of Health postdoctoral research fellowship.

${ }^{3}$ To whom correspondence should be addressed at Neurology Service, Massachusetts General Hospital, Boston, MA 02114.
}

cological studies with synthetic somatostatin have demonstrated a direct effect on neuronal activity (Renaud et al., 1975) and a modification of behavior in intact animals (Rorstad et al., 1980). In view of these findings, it has been postulated that somatostatin functions as a neurotransmitter or neuromodulator in addition to its role as a hypothalamic releasing hormone.

Somatostatin has been identified by radioimmunoassay (RIA) in human cerebrospinal fluid (CSF) (Patel et al., 1977; Kronheim et al., 1977), but little is known about the temporal patterns of this peptide in that system. The purpose of this study was to identify the somatostatinlike immunoreactivity in CSF from the rhesus monkey and to determine the temporal profiles of CSF somatostatin during different environmental lighting conditions.

\section{Materials and Methods}

Animals. Adult male rhesus monkeys were purchased from the National Institutes of Health primate colony and were adapted to chronic chair restraint as previously described (Reppert et al., 1979). The animals were exposed to 3 to 4 days of diurnal lighting ( $12 \mathrm{hr}$ light, $12 \mathrm{hr}$ dark), with lights on from 6 A.M. to 6 P.M., followed by 3 to 4 days of constant light and another 4 days of constant dark. CSF was withdrawn continuously (1 ml/ $\mathrm{hr}$ ) from an indwelling cisternal subarachnoid catheter 
using methods previously described (Reppert et al., 1979); 2-ml fractions were collected. The refrigerated samples were removed every $24 \mathrm{hr}$ and stored at $-70^{\circ} \mathrm{C}$. Neither 24-hr refrigerator storage nor repeated (three times) freeze-thawing of pooled monkey CSF significantly affected the level of somatostatin measured by RIA.

Materials. The sources of the peptides used are as follows: somatostatin for immunization, dihydrosomatostatin, $N$-Tyr-somatostatin, [Tyr ${ }^{12}$ ]somatostatin, bradykinin triacetate, leucine enkephalin, methionine enkephalin, neurotensin, angiotensin, bombesin, adrenocorticotropic hormone-1-24 $\left(\mathrm{ACTH}_{1-24}\right)$, oxytocin, thyrotropinreleasing hormone (TRH), and substance $\mathrm{P}$, Bachem (Torrance, CA); somatostatin for RIA standard, [Tyr $\left.{ }^{1}\right]$ somatostatin, luteinizing hormone-releasing hormone (LHRH), Beckman (Palo Alto, CA): vasoactive intestinal polypeptide (VIP), motilin, cholecystokinin (CCK)-octapeptide, and secretin, Peninsula (San Carlos, CA); porcine glucagon, $\alpha$-melanocyte-stimulating hormone $(\alpha-$ MSH), and melatonin, Sigma (St. Louis, MO); Arg-vasotocin, Merck (West Point, PA); Arg-vasopressin, Ferring A/B (Malmö, Sweden); $\operatorname{des}\left[\mathrm{Ala}^{1}, \mathrm{Gly}^{2}, \mathrm{NH}_{2}^{3}\right.$, $\left.\mathrm{COOH}^{14}\right]$ somatostatin and $\operatorname{des}\left[\mathrm{NH}_{2}^{1}, \mathrm{COOH}^{14}\right]$ somatostatin, Ayerst (Montreal, Quebec, Canada); [Ser $\left.{ }^{10}\right]$ somatostatin, $N^{3}$-acetyl des[Ala ${ }^{1}$, Gly $\left.{ }^{2}\right]$ somatostatin, and bisacrylamide des $\left[\mathrm{Ala}^{1}, \mathrm{Gly}^{2}\right]$ somatostatin, Dr. A. Schonbrunn, Harvard School of Public Health (Boston, MA); the alanine-substituted somatostatin analogues in Table I, Dr. J. Rivier, Salk Institute (La Jolla, CA); somatostatin-28, Drs. P. Brazeau and N. C. Ling, Salk Institute; rat insulin, Dr. R. Chance, Eli Lilly Laboratories (Indianapolis, IN); and rat GH, rat prolactin (PRL), rat thyrotropin-stimulating hormone (TSH), human GH, and human PRL, National Institute of Arthritis, Metabolism, and Digestive Diseases (Bethesda, MD).

The sources of the following reagents are as follows: human serum albumin (HSA; Cohn fraction V) and horse heart cytochrome $c$ (Type III), Sigma; $\mathrm{Na}\left[{ }^{125} \mathrm{I}\right]$, Amersham (Arlington Heights, IL); normal rabbit serum, PelFreeze Biologicals (Rogers, AR); and goat anti-rabbit $\gamma$ globulin, Biotek (Shawnee Mission, KS).

RIA for somatostatin. Antiserum for somatostatin was generated in a New Zealand white rabbit using methods previously described (Arnold and Fernstrom, 1980). RIA was performed using a 1:150,000 final dilution of rabbit antiserum (batch M4) and approximately $10^{4} \mathrm{cpm}$ of ${ }^{125}$ I-labeled [ $\left.\mathrm{Tyr}^{1}\right]$ somatostatin (Schonbrunn and Tashjian, 1978) in a final volume of $0.6 \mathrm{ml}$ with an assay buffer of $0.1 \mathrm{M}$ sodium phosphate, $\mathrm{pH} 7.4$, containing $0.01 \mathrm{M}$ EDTA, $0.05 \mathrm{M} \mathrm{NaCl}, 0.02 \%$ sodium azide, and $0.1 \% \mathrm{HSA}$. Assay tubes containing standards $(1.25$ to $320 \mathrm{pg}$ of somatostatin) or samples of $0.2 \mathrm{ml}$ of CSF were incubated at $4^{\circ} \mathrm{C}$ for $24 \mathrm{hr}$ before the addition of $0.15 \mathrm{ml}$ of appropriately diluted normal rabbit serum and goat anti-rabbit $\gamma$-globulin. After an additional $24-\mathrm{hr}$ incubation, the assay tubes were centrifuged and the radioactivity in the pellet was determined.

Gel permeation chromatography. Pooled monkey CSF $(30 \mathrm{ml})$ was lyophilized, reconstituted in $2 \mathrm{ml}$ of $1 \mathrm{M}$ acetic acid, and added to a $0.9 \times 50 \mathrm{~cm}$ column of BioGel P-10. 'The column was eluted with $1 \mathrm{M}$ acetic acid at $4^{\circ} \mathrm{C} ; 1-\mathrm{ml}$ fractions were collected. Fractions were lyoph- ilized, reconstituted in $1 \mathrm{ml}$ of RIA buffer, and assayed for somatostatin.

Data analysis. Periodicity in CSF somatostatin immunoreactivity was evaluated by power spectral analysis (Terman and Terman, 1980) for each animal in each of the test periods (light/dark, constant light, or constant dark). A computer program transformed the 2 -hr values for immunoreactive somatostatin (IRS) to relative deviations from a least squares regression line fitted to the data sample. The correlation of the data with sine and cosine functions was determined independently for a succession of test periods between 2 and $30 \mathrm{hr}$ in $0.05-\mathrm{hr}$ increments. The magnitude of the best fitting sine function for each test period was defined as $M=$ $\sqrt{r_{\mathrm{sin}}^{2}+r_{\mathrm{cos}}^{2}}$, and the peak phase was defined by $\phi=$ $\tan ^{-1}\left(r_{\mathrm{sin}} / r_{\mathrm{cos}}\right)$. The spectra were expressed graphically in terms of spectral power, $M^{2}$. A one-tailed $t$ test was used to evaluate the significance of the spectral components $(p<0.01$ was chosen as the minimum level of significance).

\section{Results}

RIA of somatostatin. The displacement of labeled somatostatin by varying amounts of standard somatostatin or other peptides is shown in Figure 1. The only peptide tested clearly showing cross-reactivity was bradykinin triacetate; this peptide was less than $0.01 \%$ as potent as somatostatin at displacing ${ }^{125}$ I-labeled [ $\mathrm{Tyr}^{1}$ ] somatostatin from rabbit antiserum. On the other hand, native bradykinin at concentrations up to $0.94 \mathrm{~mol} / \mathrm{liter}$ $\times 10^{-6}$ showed no cross-reactivity.

The immunological cross-reactivity of a number of analogues of somatostatin is presented in Table I. The substitution of alanine for a single amino acid in the central portion of the somatostatin molecule (e.g., amino acids 6 to 12) results in substantially diminished crossreactivity. Alterations of the $\mathrm{NH}_{2}$-terminal portion of the somatostatin molecule (by substituting alanine for amino acids 2 or 4 or adding an $\mathrm{NH}_{2}$-terminal tyrosine) did not affect its immunoreactivity greatly. Somatostatin-28 is equipotent with somatostatin-14 on a molar basis (Fig. 2).

The sensitivity of the RIA, defined as the concentration of somatostatin which resulted in the binding of labeled somatostatin $2 \mathrm{SD}$ below mean binding in the absence of somatostatin, was $1.3 \mathrm{pg} /$ tube. The $\mathrm{ED}_{50}$ for somatostatin (defined as the concentration of somatostatin required to displace $50 \%$ of ${ }^{125}$ I-labeled [Tyr ${ }^{1}$ ]somatostatin specifically bound to antiserum) in the RIA was $3.5 \times 10^{-11} \mathrm{~mol} / \mathrm{liter}(34.4 \mathrm{pg} /$ tube). The interassay coefficients of variation for samples containing means of 52 , 25 , and $12 \mathrm{pg} /$ tube were $11.4,12.7$, and $10.6 \%$, respectively. The intra-assay coefficient of variation was less than $10 \%$.

The inhibition curve for serial dilutions of pooled monkey CSF was compared with a standard curve using synthetic somatostatin. The resultant $\log _{e}$-logit slopes of the inhibition curves for the somatostatin standard $(-1.22)$ and monkey CSF $(-1.19)$ were not significantly different $(p<0.05)$.

Gel permeation chromatography. Chromatography of pooled monkey CSF on a Bio-Gel P-10 column revealed five major peaks of immunoreactivity (Fig. 3). Peak IV 


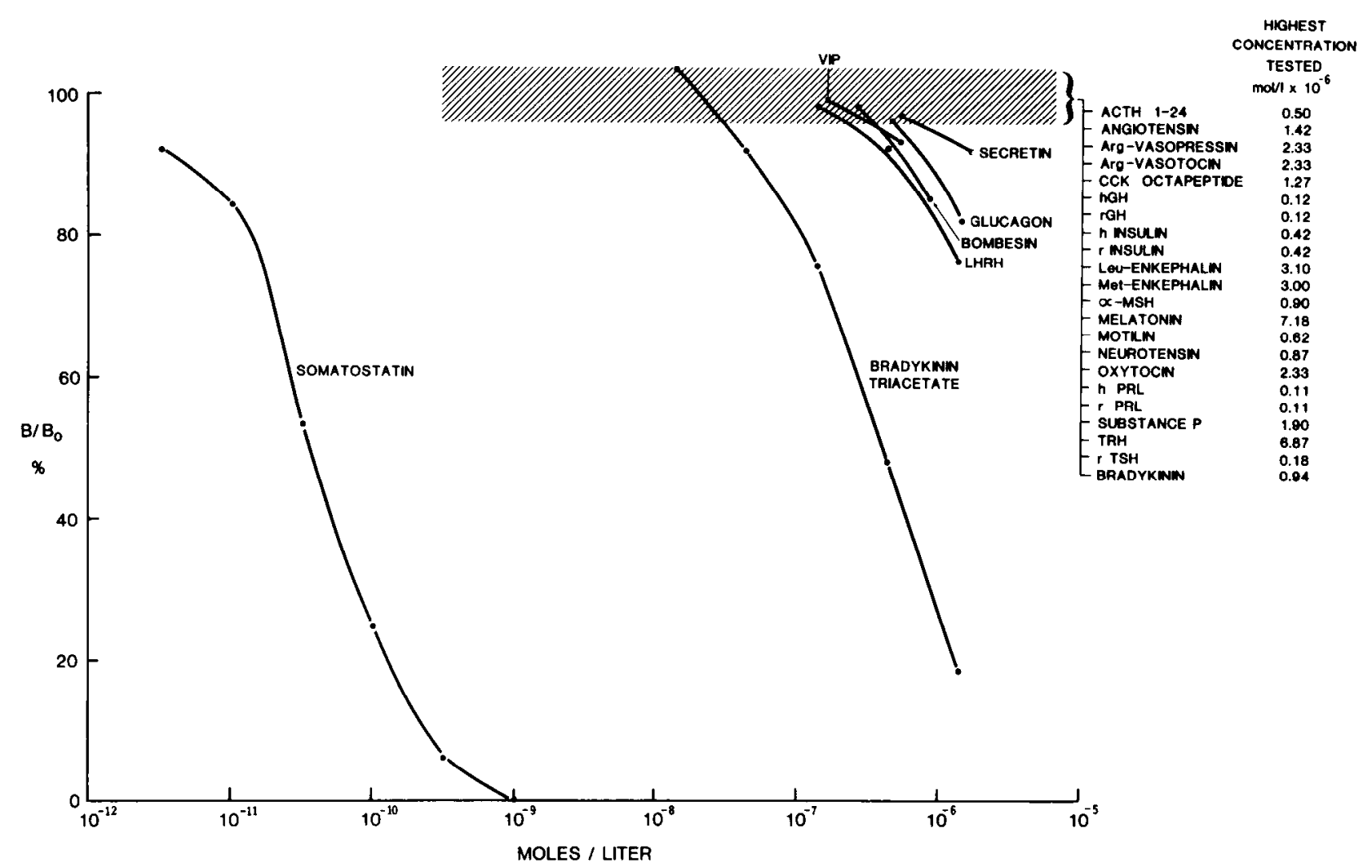

Figure 1. Binding of ${ }^{125} \mathrm{I}$-labeled $\left[\mathrm{Tyr}^{1}\right]$ somatostatin to rabbit antiserum as a function of somatostatin or other peptide concentrations (moles per liter). $B / B_{0}$, Ratio of ${ }^{125}$ I-labeled [Tyr ${ }^{1}$ ]somatostatin bound in the presence of competing peptide to that bound in the absence of competing peptide; $h$, human; $r$, rat.

represents material that co-chromatographs with synthetic somatostatin, whereas peak $I I I$ behaves similarly to somatostatin-28. Peak I migrates approximately with cytochrome $c\left(M_{\mathrm{r}}=12,300\right)$; peak II migrates intermediate between cytochrome $c$ and somatostatin-28. The remaining material (peak $V$ ) migrates after synthetic somatostatin. The proportion of somatostatin immunoreactivity measured in peaks $I$ to $V$ is $22,24,26,13$, and $15 \%$, respectively.

CSF somatostatin. CSF samples obtained continuously from five monkeys over the three lighting schedules were assayed for somatostatin immunoreactivity (Figs. 4 and 5). IRS levels in CSF ranged from 7 to $117 \mathrm{pg} / \mathrm{ml}$.

Periodicity in CSF IRS levels was evaluated by power spectral analysis for each animal during each of the three lighting conditions (Fig. 6). Ultradian components to CSF IRS periodicity were observed in all monkeys tested during each of the three lighting regimens (Fig. 5). These components ranged from 3.35 to $16.60 \mathrm{hr}$ in duration and generated a pattern of periodicity which varied from animal to animal. However, during diurnal lighting, all five monkeys had a clear ultradian component of 4 to 5 $\mathrm{hr}$ in duration. This rhythm persisted during constant light in three of the monkeys (animals 615, 854, and 771) and in constant darkness in four monkeys (animals 585, 641,854 , and 771).

During diurnal lighting conditions, three of the five monkeys (animals 585,615 , and 771 ) had a significant ( $p$ $<0.01$ ) daily component (between 23 and $24 \mathrm{hr}$ ) in their CSF IRS levels. In each of these three animals, higher levels of IRS generally were observed during the dark period of the daily cycle. Of the remaining two monkeys, one (animal 641) had a significant rhythmic component of $20.95 \mathrm{hr}$, while the other (animal 854) did not have a significant daily component during diurnal lighting conditions. Exposure of the monkeys to constant conditions modified the daily periodicity of CSF somatostatin in some of the animals. During constant light, only one monkey (animal 615) had a significant rhythmic component of near $24 \mathrm{hr}$ duration $(22.70 \mathrm{hr})$. In a monkey (animal 585) which previously had a significant daily component $(23.95 \mathrm{hr})$ during diurnal lighting conditions, constant light abolished a daily rhythmic component but generated a shorter component of $20.70 \mathrm{hr}$ duration. During the subsequent exposure to constant darkness, two monkeys (animals 615 and 771 ) had a significant daily component in CSF somatostatin of 22.75 and 24.90 $\mathrm{hr}$, respectively.

\section{Discussion}

This study provides evidence for the existence of multiple forms of somatostatin in monkey CSF. By gel permeation chromatography, five peaks of somatostatin immunoreactivity have been identified. Peak IV corresponds to the tetradecapeptide somatostatin, whereas Peaks $I I I$ and $I$ reflect higher molecular weight species of approximately 3,000 and 12,000 daltons, respectively. Peak II also reflects larger molecular weight material intermediate between 3,000 and 12,000 daltons. By its elution positions, peak $V$ may represent a molecular species smaller than the native tetradecapeptide. In the literature, a host of studies have dealt with the identifi- 
TABLE I

Immunoreactivity of somatostatin analogues

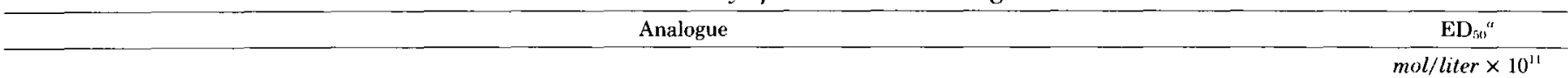

Somatostatin

Dihydrosomatostatin

$N$-Tyr-somatostatin

[Tyr'] Somatostatin

[Ala"] Somatostatin

$\left[\mathrm{Ala}^{4}\right]$ Somatostatin

[Ala ${ }^{6}$ ] Somatostatin

$\left[\mathrm{Ala}^{7}\right]$ Somatostatin

8,000

24,000

Ala ${ }^{8}$ Somatostatin

[Ala" $]$ Somatostatin

["Tyr"]Somatostatin

[Ala ${ }^{12}$ ]Somatostatin

$\left[\mathrm{Ala}^{1.3}\right]$ Somatostatin

$N^{3}$-Acetyl des[Ala', Gly $\left.{ }^{2}\right]$ somatostatin

Bisacrylamide des[ $\left.\mathrm{Ala}^{1}, \mathrm{Gly}^{2}\right]$ somatostatin

„HC-CO-Ser-Thr-Phe-Thr-Lys-Trp-Phe-Phe-Asn-Lys-NH-CH

$$
{ }_{2} \mathrm{HC}-\mathrm{CO}-\mathrm{Ser}-\mathrm{Th} \text {-Phe-Thr-Lys-Trp-Phe-Phe-Asn-Lys-NH-CH}
$$

$\begin{array}{ccccccccccc}2 & 3 & 4 & 5 & 6 & 7 & 8 & 9 & 10 & 11 & 12 \\ \text { Retroenantio isomer of } \operatorname{des}\left[\mathrm{Ala}^{1},\right. & \mathrm{Gly}^{2}, \mathrm{NH}_{2}^{3}, & \left.\mathrm{COOH}^{14}\right] \text { somatostatin }\end{array}$

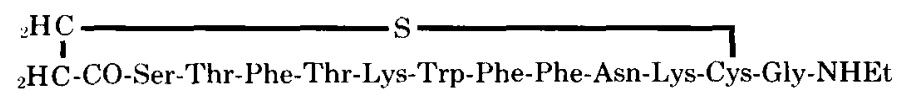

$\begin{array}{llllllllllllll}1 & 2 & 3 & 4 & 5 & 6 & 7 & 8 & 9 & 10 & 11 & 12 & 13 & 11\end{array}$

Retroenantio isomer of $\operatorname{des}\left[\mathrm{NH}_{2}^{1}, \mathrm{COOH}^{14}\right]$ somatostatin

${ }^{a} \mathrm{ED}_{\mathrm{s}, 0}$, concentration of somatostatin or analogue required to displace $50 \%$ of $\left[{ }^{125} \mathrm{I}^{\mathrm{T}} \mathrm{Tyr}{ }^{1}\right]$ somatostatin specifically bound to antiserum.

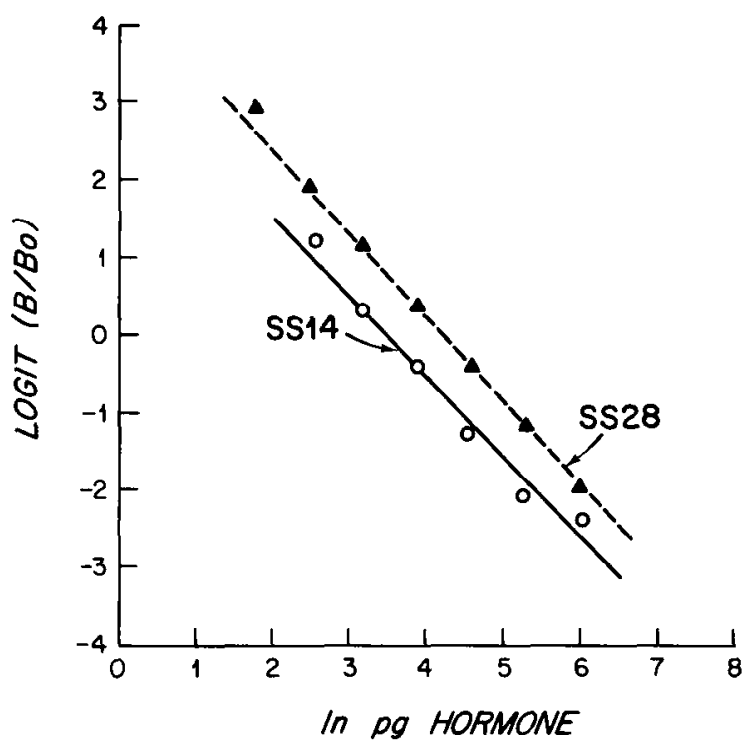

Figure 2. Radioimmunoassay standard curves were run with synthetic somatostatin-14 $(\mathrm{O})$ and somatostatin-28 (A) using the primary antiserum at a dilution of 1:120,000. Straight lines were fitted by a weighted least squares regression of logit $(B /$ $B_{0}$ ) on $\log _{e}$ (dose) (Davis et al., 1980). The $50 \%$ binding values were $19.84 \pm 1.68 \mathrm{fmol} /$ tube for somatostatin-14 and $21.57 \pm$ $0.51 \mathrm{fmol} /$ tube for somatostatin-28. The corresponding slopes were $-1.044 \pm 0.063$ and $-1.097 \pm 0.020$, respectively.

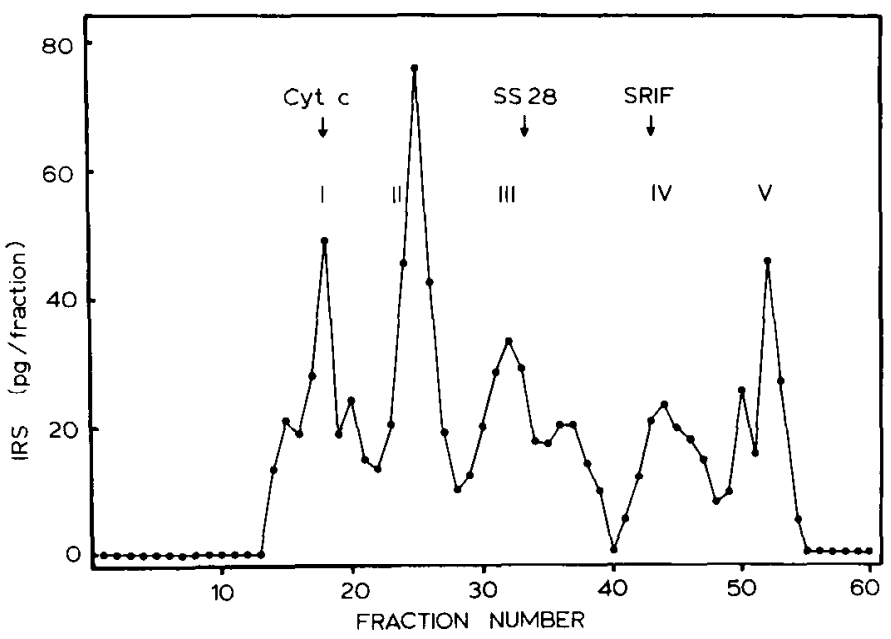

Figure 3. Gel permeation chromatography of pooled monkey CSF on a Bio-Gel P-10 column. The vertical arrows indicate the elution volumes of $C y t c$ (horse heart cytochrome $c ; M_{\mathrm{r}}=$ 12,300), SS 28 (somatostatin-28), and SRIF (somatostatin).

cation of multiple species of somatostatin in mammalian brain and gut extracts. In addition to isolating the 1,600dalton somatostatin molecule, various workers have identified 12,000-dalton and 3,000- to 4,000-dalton species (Zyznar et al., 1979; Trent and Weir, 1981), an interme- 


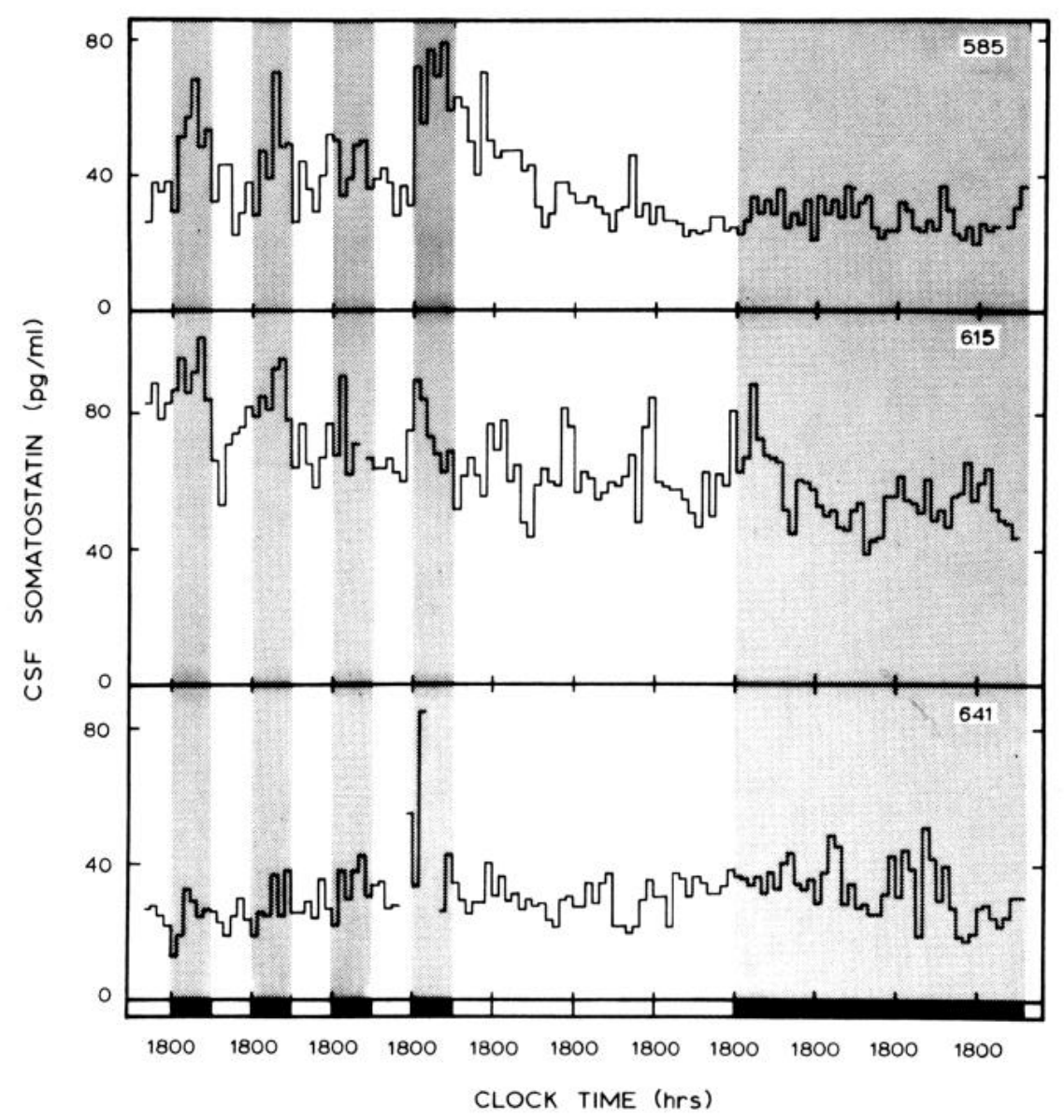

Figure 4. Patterns of CSF somatostatin from three monkeys (animals 585, 615 , and 641) during periods of diurnal lighting, constant light, and constant dark. CSF was collected as 2-hr fractions.

diate species of approximately 6,000 daltons (Lauber et al., 1979; Sagar et al., 1982), and a species smaller than 1,600 daltons (Rorstad et al., 1979). Our finding of multiple forms of somatostatin in monkey CSF differs from a report identifying a single species of somatostatin (the tetradecapeptide) in human CSF (Kronheim et al., 1977). Whether this reflects a difference in experimental protocol or in species cannot be firmly established at this time. Most likely, the presence of multiple species of somatostatin in monkey CSF suggests that axon terminals that release somatostatin into CSF release many forms of the molecule. However, the chromatographic conditions used in this study cannot rule out the possibility that the immunoreactive material of higher apparent molecular weight than synthetic somatostatin consists either of somatostatin oligomers or of somatostatin bound to some other material.

With the use of a sensitive and specific assay for somatostatin, this study describes the temporal pattern of CSF somatostatin immunoreactivity in the rhesus monkey. IRS levels in CSF varied markedly over the period of observation, with a range of 7 to $117 \mathrm{pg} / \mathrm{ml}$. The periodicity of CSF somatostatin immunoreactivity was evaluated by power spectral analysis. By this method, all monkeys in this study exhibited ultradian components in CSF IRS rhythms. Of particular interest is the 4 - to 5 - $\mathrm{hr}$ periodicity in all monkeys tested during diurnal lighting conditions. This ultradian component by and large was well maintained during constant lighting conditions. Interestingly, Steiner et al. (1978) have described a serum GH rhythm with a periodicity of $4.1 \mathrm{hr}$ in another Old World primate, the baboon. In a recent study, Quabbe et al. (1981) describe a similar pattern of $\mathrm{GH}$ secretion in the rhesus monkey. Whether CSF somatostatin has a physiological role in $\mathrm{GH}$ regulation has yet to be determined, although a recent study (Lumpkin et al., 1981) finds that the intraventricular injection of somatostatin paradoxically stimulates GH release. Indeed, it is conceivable that CSF provides a physiological medium for hormonal communication with peptides such as somatostatin between various brain neurons.

Three of the five animals had a daily (23- to 24-hr) component for CSF IRS during diurnal lighting conditions, with higher peptide levels during the dark periods. Exposure to constant light or constant dark resulted in a loss of daily periodicity in all but one or two animals.

The significance of both ultradian and daily rhythmicity in CSF IRS cannot be firmly established at this time. It has been suggested that the measurement of the CSF peptide level is probably reflective of the diffusion of molecules following synaptic release by brain neurons or the result of direct secretion by these cells into CSF (Jackson, 1980). In the frog, it has been demonstrated that the ependymal cells in the median eminence have 


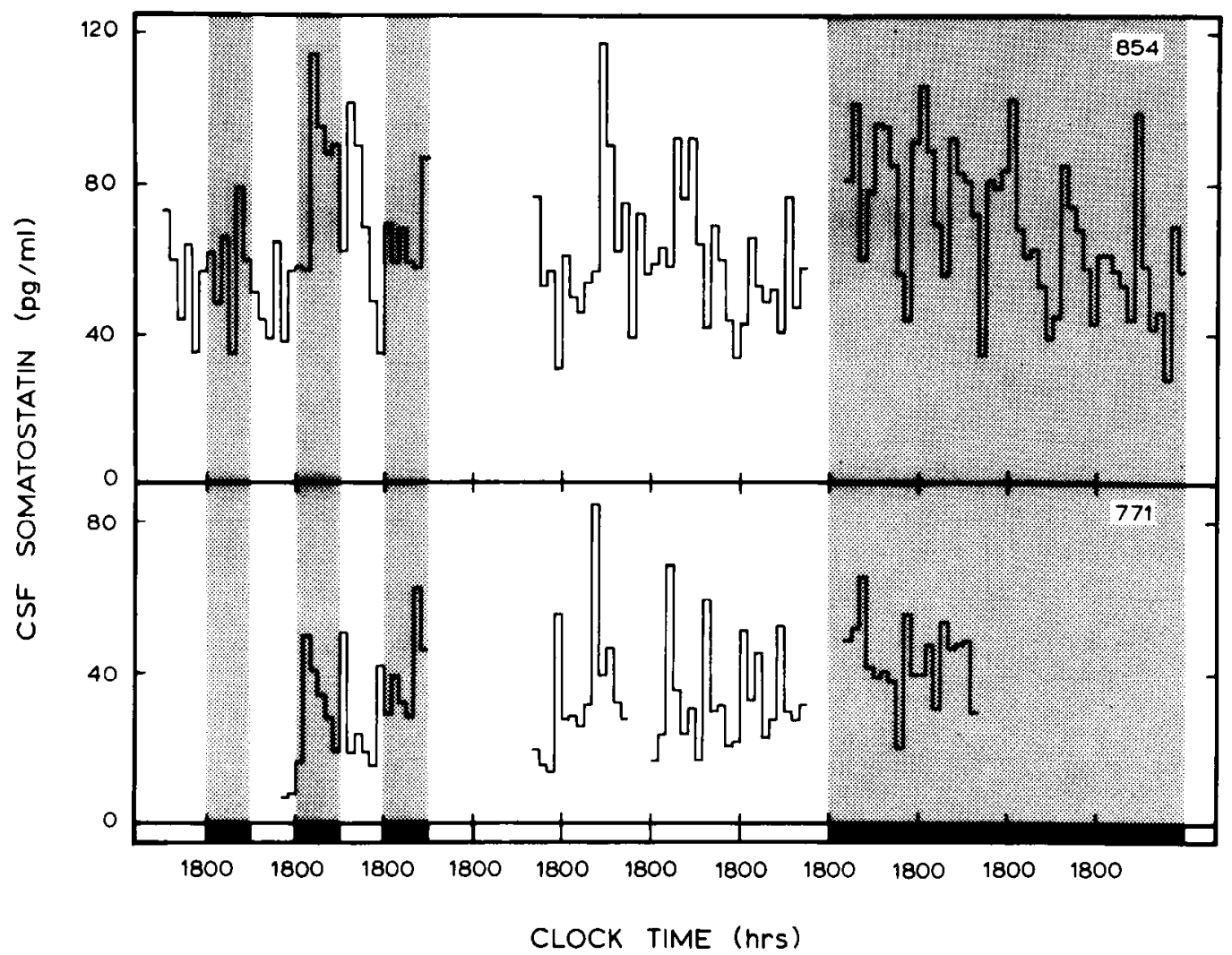

Figure 5. Patterns of CSF somatostatin from two monkeys (animals 854 and 771) during periods of diurnal lighting, constant light, and constant dark. CSF was collected as 2-hr fractions.
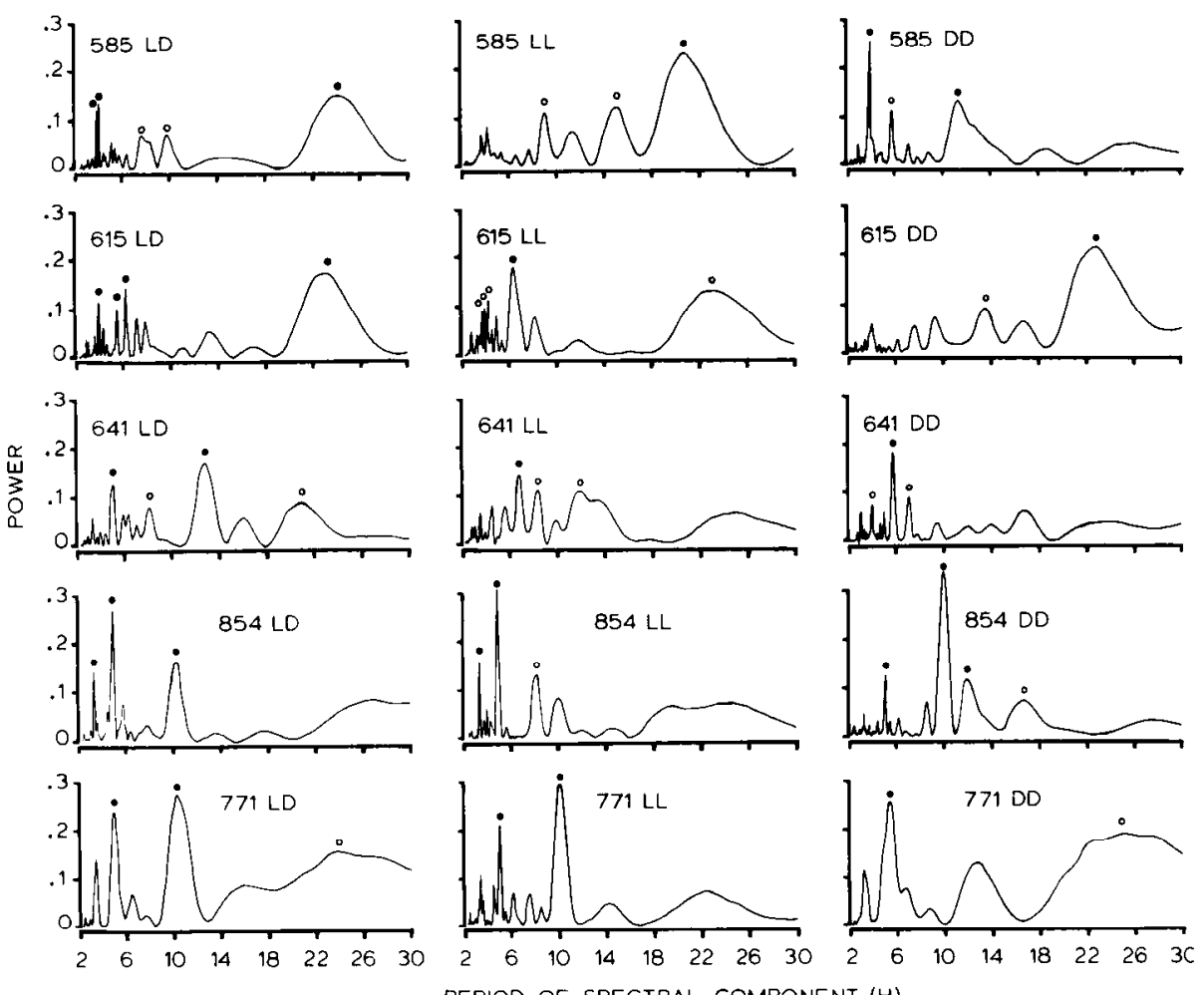

Figure 6. Power spectra for periodicity in CSF somatostatin in five monkeys (animals 585, 615, 641, 854, and 771) during each of three lighting conditions: $L D$ (12 hr light, $12 \mathrm{hr}$ dark), $L L$ (constant light), and $D D$ (constant dark). component significant at $p<0.001 ; 0, p<0.01$. 
bidirectional transport activities for the transport of substances between hypophysial portal blood and CSF (Nakai and Naito, 1974). It is unlikely, however, that CSF peptide levels are indicative of simple diffusion of these water-soluble molecules from blood across a blood-brain barrier into CSF (Jackson, 1980).

Interestingly, two recent reports document dramatic daily rhythms in CSF levels of the neuropeptides oxytocin and vasopressin in the monkey and the cat (Reppert et al., 1981; Perlow et al., 1981). Whether CSF rhythms are common to all neuropeptides is unknown at present, although subsequent investigation on this topic is already underway.

Note added in proof. After submission of this paper, a report by Berelowitz et al. (1981) appeared which also describes a nocturnal elevation in IRS in the rhesus monkey.

\section{References}

Arnold, M. A., and J. D. Fernstrom (1980) Administration of antisomatostatin serum to rats reverses the inhibition of pulsatile growth hormone secretion produced by injection of metergoline but not yohimbine. Neuroendocrinology 31: 194199.

Berelowitz, M., M. J. Perlow, H. J. Hoffman, and L. A. Frohman (1981) The diurnal variation of immunoreactive thyrotropinreleasing hormone and somatostatin in the cerebrospinal fluid of the rhesus monkey. Endocrinology 109: 2102-2109.

Brazeau, P., W. Vale, R. Burgus, N. Ling, M. Butcher, J. Rivier, and R. Guillemin (1973) Hypothalamic peptide that inhibits the secretion of immunoreactive pituitary growth hormone. Science 179: 77-79.

Brownstein, M. J., A. Arimura, M. Sato, A. V. Schally, and J. Kizer (1975) The regional distribution of somatostatin in the rat brain. Endocrinology 96: 1456-1461.

Davis, S. E., M. L. Jaffe, P. J. Manson, and D. Rodbard (1980) RIA data processing with a small programmable calculator. J. Radioimmunoassay $1: 15-25$.

Epelbaum, J., P. Rrazeau, D. Tsang, .J. Brawer, and J. B. Martin (1977) Subcellular distribution of radioimmunoassayable somatostatin in rat brain. Brain Res. 126: 309-323.

Jackson, I. M. D. (1980) Significance and function of neuropeptides in cerebrospinal fluid. In Neurobiology of Cerebrospinal Fluid: I, J. H. Wood, ed., p. 632, The Plenum Publishing Corp., New York.

Kobayashi, R. M., M. Brown, and W. Vale (1977) Regional distribution of neurotensin and somatostatin in rat brain. Brain Res. 126: 584-588.

Kronheim, S., M. Berelowitz, and B. L. Pimstone (1977) The presence of immunoreactive growth hormone release-inhibiting hormone in normal cerebrospinal fluid. Clin. Endocrinol. (Oxf.) 6: 411-415.

Lauber, M., M. Camier, and P. Cohen (1979) Higher molecular weight forms of immunoreactive somatostatin in mouse hypothalamic extracts: Evidence for processing in vitro. Proc. Natl. Acad. Sci. U. S. A. 76: 6004-6008.

Lumpkin, M. D., A. Negro-Vilar, and S. M. McCann (1981) Paradoxical elevation of growth hormone by intraventricular somatostatin: Possible ultrashort-loop feedback. Science 211: 1072-1074.

Nakai, Y., and N. Naito (1974) Endocytic uptake and transport of intravascularly injected peroxidase by ependymal cells of the frog median eminence. J. Electron Microsc. (Tokyo) 23: 19-32.

Palkovits, M., M. S. Brownstein, A. Arimura, H. Sato, A. V. Schally, and J. S. Kizer (1979) Somatostatin content of the hypothalamic ventromedial and arcuate nuclei and the circumventricular organs of the rat. Brain Res. 109: 430-434.

Patel, Y. C., K. Rao, and S. Reichlin (1977) Somatostatin in human cerebrospinal fluid. N. Engl. J. Med. 296: 529-533.

Perlow, M. J., S. M. Reppert, H. G. Artman, and S. M. Seif (1981) Oxytocin, vasopressin, vasotocin and estrogen-stimulated neurophysin: Daily pattern in plasma and cerebrospinal fluid concentrations and response to estrogen stimulation. In Proceedings of the 63rd Annual Meeting of the Endocrine Society, Cincinnati, $\mathrm{OH}$, Abstr. 760, The Endocrine Society, Bethesda, MD.

Quabbe, H. -J., M. Gregor, C. Bumke-Vogt, A. Eckhof, and I. Witt (1981) Twenty-four-hour pattern of growth hormone secretion in the rhesus monkey: Studies including alterations in the sleep/wake and sleep stage cycles. Endocrinology 109: 513-522.

Renaud, L. P., J. B. Martin, and P. Brazeau (1975) Depressant action of TRH, LHRH and somatostatin on activity of central neurons. Nature 255: 233-235.

Reppert, S. M., M. J. Perlow, L. Tamarkin, and D. C. Klein (1979) A diurnal melatonin rhythm in primate cerebrospinal fluid. Endocrinology 104: 295-301.

Reppert, S. M., H. G. Artman, S. Swaminathan, and D. A. Fisher (1981) Vasopressin exhibits a rhythmic daily pattern in cerebrospinal fluid but not in blood. Science 213: 12561257.

Rorstad, O. P., J. Epelbaum, P. Brazeau, and J. B. Martin (1979) Chromatographic and biological properties of immunoreactive somatostatin in hypothalamic and extrahypothalamic brain regions of the rat. Endocrinology 105: 1083-1092.

Rorstad, O. P., J. B. Martin, and L. C. Terry (1980) Somatostatin and the nervous system. In The Role of Peptides in Neuronal Function, J. L. Barker and T. G. Smith, Jr., eds., p. 595, Marcel Dekker, New York.

Sagar, S. M., D. Landry, W. J. Millard, T. M. Badger, M. A. Arnold, and J. B. Martin (1982) Depletion of somatostatinlike immunoreactivity in the rat central nervous system by cysteamine. J. Neurosci. 2: 225-231.

Schonbrunn, A., and A. H. Tashjian, Jr. (1978) Characterization of functional receptors for somatostatin in rat pituitary cells in culture. J. Biol. Chem. 253: 6473-6483.

Steiner, R. A., J. K. Stewart, J. Barber, D. Koerker, C. J. Goodner, A. Brown, P. Illner, and C. C. Gale (1978) Somatostatin: A physiological role in the regulation of growth hormone secretion in the adolescent male baboon. Endocrinology 102: 1587-1594.

Terman, J. S., and M. Terman (1980) Effects of illumination levels on the rat's rhythmicity of brain self-stimulation behavior. Behav. Brain Res. 1: 507-519.

Trent, D. F., and G. C. Weir (1981) Ileterogeneity of somatostatin-like peptides in rat brain, pancreas, and gastrointestinal tract. Endocrinology 108: 2033-2038.

Vale, W., C. Rivier, P. Brazeau, and R. Guillemin (1974) Effects of somatostatin on the secretion of thyrotropin and prolactin. Endocrinology 95: 968-977.

Zyznar, E. S., J. M. Conlon, V. Schusdziarra, and R. H. Unger (1979) Properties of somatostatin-like immunoreactive polypeptides in the canine extrahypothalamic brain and stomach. Endocrinology 105: 1426-1431. 